\title{
Moderate alcohol consumption is associated with better endothelial function: a cross sectional study
} Keiko Suzuki1, Mitchell SV Elkind2, Bernadette Boden-Albala2,3, Zhezhen Jin ${ }^{4}$, Grace Berry ${ }^{1}$, Marco R Di Tullio ${ }^{1}$, Ralph L Sacco ${ }^{1,5}$ and Shunichi Homma*1

\begin{abstract}
Address: ${ }^{1}$ Division of Cardiology, Department of Medicine, Columbia University College of Physicians and Surgeons, 630 West 168 th Street, New York, NY, USA, 2Department of Neurology, Columbia University College of Physicians and Surgeons and Mailman School of Public Health, 630 West 168th Street, New York, NY, USA, ${ }^{3}$ Department of Sociomedical Science, Mailman School of Public Health, Columbia University College of Physicians and Surgeons, 630 West 168th Street, New York, NY, USA, ${ }^{4}$ Department of Biostatistics, Mailman School of Public Health, Columbia University College of Physicians and Surgeons, 722 West 168th Street, New York, NY, USA and ${ }^{5}$ Department of Neurology, University of Miami, Miller School of Medicine, 1120 Northwest 14th Street, Miami, FL, USA
\end{abstract}

Email: Keiko Suzuki - majokko7174@gmail.com; Mitchell SV Elkind - MSE13@columbia.edu; Bernadette Boden-Albala -bb87@columbia.edu; Zhezhen Jin - zj7@columbia.edu; Grace Berry - gb2221@columbia.edu; Marco R Di Tullio - md42@columbia.edu;

Ralph L Sacco - RSacco@med.miami.edu; Shunichi Homma* - sh23@columbia.edu

* Corresponding author

Published: 20 February 2009

BMC Cardiovascular Disorders 2009, 9:8 doi:10.1/86/147I-226I-9-8

This article is available from: http://www.biomedcentral.com/|47|-226|/9/8

(c) 2009 Suzuki et al; licensee BioMed Central Ltd.

This is an Open Access article distributed under the terms of the Creative Commons Attribution License (http://creativecommons.org/licenses/by/2.0), which permits unrestricted use, distribution, and reproduction in any medium, provided the original work is properly cited.

\begin{abstract}
Background: Moderate alcohol consumption is protective against coronary artery disease. Endothelial dysfunction contributes to atherosclerosis and the pathogenesis of cardiovascular disease. The effects of alcohol consumption on endothelial function may be relevant to these cardiovascular outcomes, but very few studies have examined the effect of alcohol consumption on endothelial function assessed by flow-mediated dilation (FMD) of the brachial artery in humans.
\end{abstract}

Methods: In the population-based Northern Manhattan Study (NOMAS), we performed a crosssectional analysis of lifetime alcohol intake and brachial artery FMD during reactive hyperemia using high-resolution B-mode ultrasound images among 884 stroke-free participants (mean age 66.8 years, women $56.6 \%$, Hispanic $67.4 \%$, black 17.4\%, and white 15.2\%).

Results: The mean brachial FMD was $5.7 \%$ and the median was $5.5 \%$. Compared to non-drinkers, those who drank >I drink/month to 2 drinks/day were more likely to have FMD above the median FMD (5.5\%) (unadjusted OR 1.7, $95 \% \mathrm{Cl}$ I.2-2.4, $\mathrm{p}=0.005$ ). In multivariate analysis, the relationship between moderate alcohol consumption and FMD remained significant after adjusting for multiple traditional cardiovascular risk factors, including sex, race-ethnicity, body mass index, diabetes mellitus, coronary artery disease, Framingham risk score, medication use (adjusted OR I.8, $95 \% \mathrm{Cl}$ I.I-3.0, $\mathrm{P}=0.03$ ). No beneficial effect on FMD was seen for those who drank more than 2 drinks/day.

Conclusion: In conclusion, consumption of up to 2 alcoholic beverages per day was independently associated with better FMD compared to no alcohol consumption in this multiethnic population. This effect on FMD may represent an important mechanism in explaining the protective effect of alcohol intake on cardiovascular disease. 


\section{Background}

Epidemiologic evidence suggests that moderate alcohol consumption is associated with a reduced risk of developing coronary artery disease (CAD) [1-4]. The relationship between alcohol intake and the risk of developing CAD is a J- or U-shaped dose-response: the risk is higher in individuals not consuming any alcohol, low when alcohol consumption is low or moderate, and tends to go up again when alcohol consumption is high[5]. The mechanism underlying the cardioprotective effects of moderate alcohol consumption may involve prevention of atherogenesis through beneficial alcohol-induced changes in serum lipids, blood clotting proteins and insulin resistance[5], although not all of these changes are well understood. Endothelial dysfunction contributes to atherosclerosis and to the pathogenesis of cardiovascular disease [6,7], but few human studies have examined the effects of alcohol on endothelial function. Flow-mediated dilation (FMD) of the brachial artery assessed by high-resolution ultrasonography is widely used for the non-invasive assessment of endothelial function[8]. FMD is diminished in patients with vascular risk factors such as aging, smoking, hypertension, dyslipidemia and diabetes mellitus, and FMD improves with risk-reduction therapy[6,7]. The objective of this study was to investigate the association between alcohol consumption and endothelial function in order to explore one potential mechanism of the protective effect of alcohol intake on cardiovascular disease.

\section{Methods}

\section{Study population}

Subjects were drawn from the Northern Manhattan Study (NOMAS), an ongoing population-based prospective cohort study designed to investigate cardiovascular and stroke risk factors in a multi-ethnic sample (white, black, and Hispanic) of stroke-free individuals from northern Manhattan. Recruitment modalities have been previously published[9,10]. Briefly, between January 1998 and April 2001, high quality ultrasound images and measurements of FMD were performed in 884 participants from NOMAS participants. Written informed consent was obtained from all subjects, and the study was approved by the Institutional Review Board of Columbia University Medical Center.

\section{Baseline clinical evaluation}

Baseline evaluation was performed at enrollment as previously reported $[9,10]$. Briefly, race-ethnicity was categorized into four groups: Hispanic, non-Hispanic black, non-Hispanic white, and other. Blood was taken from fasting subjects, and standard enzymatic methods were used for the sample analyses. Cardiovascular risk factors were collected by direct interview and were defined as in the prior publication[10]. Hypertension was defined as a systolic blood pressure (SBP) recording $>140 \mathrm{mmHg}$ or diastolic blood pressure (DBP) recording $>90 \mathrm{mmHg}$ during one sitting based on the mean of two readings of the blood pressure measurements, a patient's self-report of a history of hypertension, or antihypertensive medication use. Diabetes mellitus was defined by one or more of the following: a patient's self-report of such a history, insulin use, oral hypoglycemic use, or fasting glucose $>126 \mathrm{mg} / \mathrm{dl}$. Hypercholesterolemia was defined by a patient's selfreport of hypercholesterolemia, use of lipid lowering therapy, or a fasting total cholesterol level $>240 \mathrm{mg} / \mathrm{dL}$. Body mass index was calculated as weight $(\mathrm{kg})$ divided by height $(\mathrm{m})$ squared. Coronary artery disease (CAD) was defined by self-report of history of heart attack, bypass surgery or angioplasty. Framingham risk score was computed from baseline risk factor data. This score takes into account data on age (per each 5 years), total cholesterol, high density lipoprotein cholesterol, systolic blood pressure, and cigarette smoking and estimate the 10-year risk for coronary artery disease (CAD) in each gender[11].

\section{Flow-mediated dilation assessment}

Arterial endothelial function defined as the brachial artery response to hyperemia was non-invasively assessed using high resolution B-mode ultrasonography as previously described[10]. Participants fasted for 12 hours, and also avoided exercise for at least 4-6 hours prior to the FMD examinations. The brachial artery diameter was measured $6 \mathrm{~cm}$ above the antecubital crease using a $15 \mathrm{MHz}$ liner array transducer (Phillips 5500, Andover, MA). FMD was measured as the dilator response to reactive hyperemia induced by 5 minute blood pressure cuff occlusion of the upper arm. The cuff was inflated to at least $50 \mathrm{mmHg}$ above SBP to occlude arterial flow. End-diastolic images were acquired and digitized by a frame grabber (model LG3, Scion Corporation) at baseline and 1 min after cuff deflation. A blinded reader analyzed brachial artery diameters off-line using analysis software. Three consecutive cardiac cycles were analyzed for both baseline and hyperemia studies of each subject, and the measurements averaged. FMD was expressed as percent change from rest:

FMD $=\frac{\text { brachial artery diameter at hyperemia }- \text { brachial artery diameter at baseline }}{\text { brachial artery diameterat baseline }} \times 100$

Intraobserver variability for FMD measurements was $1.3 \%$.

\section{Alcohol consumption assessment}

The alcohol consumption assessment was described previously[12,13]. Research assistants used structured in-person interviews adapted from the National Cancer Institute Food Frequency questionnaire[14] and the Willett Food Frequency questionnaire[15]. Inquiries were made about 
consumption of wine, beer and liquor on average during each participant's lifetime. The defined response regarding frequency allowed 9 possibilities ranging from never to more than 6 drinks per day. The responses for each beverage type were summed to obtain a total quantity, and an average daily quantity was calculated. A standard drink of wine was considered to contain 4 ounces, beer 12 ounces, and liquor 1.5 ounces of ethanol. The reliability and validity of alcohol assessment has been shown previously to be good in our population[12].

\section{Statistical analysis}

The categorization of alcohol consumption was the same as in the previous publications[13,1] less than 1 drink/ month; [2] 1 drink/month to 2 drinks/day; and [3] more than 2 drinks/day. All statistical analyses were performed using SAS 9.1 (SAS Institute, Cary, NC). The association between FMD and alcohol consumption was analyzed by univariate and multivariable logistic regression analyses. The dependent variable, FMD, was dichotomized using the median level of the FMD distribution.

Table I: Characteristics of study participants

\begin{tabular}{ll}
\hline Characteristic & Mean (SD) or n (\%) \\
\hline Total number & 884 \\
Age (years) & $66.8(8.8)$ \\
Men & $384(43.4)$ \\
Race-ethnicity & \\
Hispanics & $596(67.4)$ \\
Non-Hispanic Black & $154(17.4)$ \\
Non-Hispanic White & $134(15.2)$ \\
Hypertension & $603(68.2)$ \\
Diabetes Mellitus & $202(22.9)$ \\
Hyperlipidemia & $435(49.3 \%)$ \\
Current smoking & $140(16.0)$ \\
History of smoking & $478(54.1)$ \\
Body mass index (kg/m²) & $27.9(5.1)$ \\
Systolic BP (mmHg) & $143(19)$ \\
Diastolic BP (mmHg) & $84(10)$ \\
Total cholesterol (mg/dl) & $202.1(39.7)$ \\
HDL cholesterol (mg/dl) & $45.6(14.0)$ \\
LDL cholesterol (mg/dl) & $130.2(35.8)$ \\
Blood Glucose (mg/dl) & $105.0(48.8)$ \\
CAD & $74(8.4 \%)$ \\
Framingham risk score & $16.9+/-3.7$ \\
FMD(\%), mean(SD) & $5.7(3.8)$ \\
FMD(\%), median & 5.5 \\
Medications & $244(27.7 \%)$ \\
Aspirin & $162(18.4 \%)$ \\
Cholesterol lowering agents & $37(4.2 \%)$ \\
Insulin & $129(14.7 \%)$ \\
Oral hypoglycemic & $393(69.8 \%)$ \\
Medication for blood pressure & $45(5.1 \%)$ \\
ACE inhibitor & $41(4.7 \%)$ \\
Beta-Blocker & $40(4.6 \%)$ \\
Calcium channel blocker & $124(14.1 \%)$ \\
Diuretics & \\
&
\end{tabular}

\section{Results}

Table 1 shows the characteristics of the 884 participants. The mean age was 66.8 years, $43.4 \%$ were men. The mean brachial FMD was $5.7 \%$ and the median was $5.5 \%$. Table 2 shows that moderate drinkers ( 1 drink/month to 2 drinks/day) were more likely to have FMD above the median of FMD (unadjusted OR 1.7, 95\% CI 1.2-2.4, $p=$ $0.005)$ compared to non-drinkers. In multivariate analysis, the relationship between moderate lifetime alcohol consumption and FMD remained significant after adjusting for sex, race-ethnicity, body mass index, diabetes mellitus, CAD, Framingham risk score and medication use (cholesterol lowering agents, aspirin, insulin, oral hypoglycemic agents, ACE inhibitors, beta-blockers, calcium channel blockers and diuretics) (adjusted OR 1.8, $95 \%$ CI 1.1-3.0p=0.03). No beneficial effect on FMD was seen for those who drank more than 2 drinks/day.

Among the 884 study participants, 74 (8.4\%) subjects had CAD. Among those 74 subjects, 18 (24.3\%) had less than $1 \mathrm{drink} / \mathrm{month}, 44(59.5 \%)$ had $1 \mathrm{drink} / \mathrm{month}$ to 2 drinks/day, and 12 (16.2\%) had more than 2 drinks/day. Among the 810 subjects who did not have CAD, 129 (15.9\%) had less than 1 drink/month, 574 (70.9\%) had 1 drink/month to 2 drinks/day, and 107 (13.2\%) had more than 2 drinks/day. No association was found between $\mathrm{CAD}$ and alcohol consumption (Chi-square test $=4.6$ with 2 degrees of freedom, $p=$ N.S).

\section{Discussion}

Our data provide evidence that moderate alcohol consumption is associated with better FMD, independent of traditional vascular risk factors. The categorization of moderate alcohol consumption was the same as in a previous publication[13]. To the best of our knowledge, our study is the first to obtain data from a large multi-ethnic, population-based cohort showing the beneficial effect of moderate alcohol drinking on FMD. Distinctive features of our cohort are the elderly, mostly Hispanic population, a high proportion of women, high prevalence of hypertension, high body mass index, and lower than expected proportion of smokers. Other studies in selected populations have shown similar associations. For example, FMD was higher in moderate drinkers compared to non-drinkers among Japanese men with CAD[16].

Brachial artery FMD reflects NO-dependent endothelial function[17]. The synthesis of endothelial NO from Larginine is regulated by endogenous nitric oxide synthase (eNOS)[18]. The endothelium regulates vascular homeostasis and is essential for vasodilation in response to increases in blood flow-associated shear stress[19]. Endothelial dysfunction is characterized by an impaired endothelium-dependent vasodilation response and decreased production and local bioavailability of $\mathrm{NO}[6]$. 
Table 2: Odds Ratios for high FMD by categories of alcohol consumption

\begin{tabular}{|c|c|c|c|c|c|c|c|}
\hline $\begin{array}{l}\text { Average alcohol } \\
\text { consumption }\end{array}$ & & OR & $\begin{array}{l}\text { unadjusted } \\
95 \% \mathrm{Cl}\end{array}$ & $P$ & OR & $\begin{array}{l}\text { adjusted } \\
95 \% \mathrm{Cl}\end{array}$ & $P$ \\
\hline$<$ I drink/month & 147 & 1 & & & 1 & & \\
\hline I drink/m to 2 drinks/d & 618 & 1.69 & I.17-2.44 & 0.005 & 1.78 & $1.07-2.99$ & 0.03 \\
\hline$>2$ drinks/day & 119 & 1.56 & $0.96-2.54$ & N.S & 1.59 & $0.80-3.17$ & N.S \\
\hline
\end{tabular}

Adjusted for sex, race-ethnicity, body mass index, diabetes mellitus, coronary artery disease, Framingham risk score, medication use.

Impaired FMD is also associated with atherosclerosis and predisposes to CAD.

Our findings indicate the possibility that a chronic effect of moderate alcohol consumption is beneficial to endothelial function. While the acute and chronic responses of vascular endothelium to alcohol may be different, neither is fully understood. In acute interventional studies, most of which assessed the effect of wine, some reported that FMD of the brachial artery was improved several hours after ingestion of wine[20], while others observed that the polyphenolic components, rather than alcohol itself, improved FMD among healthy volunteers and patients with CAD $[21,22]$. One study reported that alcohol produced significant vasodilatation of a brachial artery at resting condition and it led to a significant increase in the artery diameter at reactive hyperemia; however, the percentage of FMD did not change in healthy subjects[23].

Previous in vitro experimental studies suggested that low concentrations of alcohol promote endothelial cell survival[24] and increase eNOS expression and NO production in both basal and flow stimulated activity [25-27]. These findings might provide a mechanism to explain the possible beneficial effect of moderate alcohol consumption on endothelial function.

Several putative biological mechanisms have been proposed to explain the cardioprotective effect of moderate alcohol consumption. Moderate alcohol consumption increases HDL, reduces platelet aggregation and fibrinogen levels, increases fibrinolysis, and also improves blood insulin sensitivity and reduces insulin resistance[5]. Although we were not able to adjust for all of these factors, our data suggest the possibility that moderate alcohol consumption directly influences endothelial function. Further research would be necessary to assess the relationship between alcohol and endothelial function both in acute and long term human research and experimental research.

This study has several limitations. First, this is a cross-sectional study, and therefore a causal relationship cannot be established. Second, the use of self-reported information on alcohol intake may have introduced misclassification of exposure, most likely an underestimation of alcohol consumption. Third, we are not able to investigate any differential effect across types of alcoholic beverages. Fourth, due to unequal distribution of reported average alcohol consumption categories, there exists a possibility that this imbalance may have affected the results. Finally, we did not examine endothelial-independent vasodilation with nitroglycerin in our cohort.

\section{Conclusion}

In conclusion, average consumption of up to 2 alcoholic beverages per day was independently associated with better FMD compared to consumption of less than 1 drink per month in this multiethnic population. This effect on FMD may represent an important mechanism in explaining the protective effect of alcohol consumption on cardiovascular disease.

\section{Competing interests}

The authors declare that they have no competing interests.

\section{Authors' contributions}

KS conceived of the study, participated in data analysis and interpretation and drafted the manuscript. MSVE participated in the design of the study, data analysis, interpretation of data, and drafting the manuscript. BB-A participated in the study coordination, data analysis and interpretation and in critical review of the manuscript. ZJ performed the statistical analysis Tand interpretation and critical review of the manuscript. GB participated in the analysis and interpretation of the data and drafting the manuscript. MRDT participated in obtaining funding for the study, the coordination of the study, analysis and interpretation of data and drafting the manuscript. RLS participated in obtaining funding for the study, the study design, data analysis and interpretation, and critically reviewed the manuscript. SH participated in the study design, data analysis and interpretation, and critically reviewed the manuscript. All authors read and approved the final manuscript.

\section{Acknowledgements}

We acknowledge the assistance of Janet DeRosa, project manager of the Northern Manhattan Study. This work was supported by grants from 
National Institute of Neurological Disorders and Stroke (R37 NS029993, stroke incidence and risk factors in a tri-ethnic region to MSVE and RLS).

\section{References}

I. Camargo CA Jr, Stampfer MJ, Glynn RJ, Grodstein F, Gaziano JM, Manson JE, Buring JE, Hennekens $\mathrm{CH}$ : Moderate alcohol consumption and risk for angina pectoris or myocardial infarction in U.S. male physicians. Ann Intern Med 1997, I 26(5):372-375

2. Rimm EB, Klatsky A, Grobbee D, Stampfer MJ: Review of moderate alcohol consumption and reduced risk of coronary heart disease: is the effect due to beer, wine, or spirits. BMJ 1996, 3 I 2(7033):73|-736.

3. Thun MJ, Peto R, Lopez AD, Monaco JH, Henley SJ, Heath CW Jr, Doll $\mathrm{R}$ : Alcohol consumption and mortality among middle-aged and elderly U.S. adults. N Engl J Med I997, 337(24): I705-17|4.

4. Doll R, Peto R, Hall E, Wheatley K, Gray R: Mortality in relation to consumption of alcohol: 13 years' observations on male British doctors. BM] 1994, 309(6959):9|I-918.

5. Hines LM, Rimm EB: Moderate alcohol consumption and coronary heart disease: a review. Postgrad Med J 200I, 77(9 I 4):747-752

6. Moens AL, Goovaerts I, Claeys MJ, Vrints CJ: Flow-mediated vasodilation: a diagnostic instrument, or an experimental tool? Chest 2005, I 27(6):2254-2263.

7. Benjamin EJ, Larson MG, Keyes MJ, Mitchell GF, Vasan RS, Keaney JF Jr, Lehman BT, Fan S, Osypiuk E, Vita JA: Clinical correlates and heritability of flow-mediated dilation in the community: the Framingham Heart Study. Circulation 2004, I09(5):613-619.

8. Corretti MC, Anderson TJ, Benjamin EJ, Celermajer D, Charbonneau F, Creager MA, Deanfield J, Drexler H, Gerhard-Herman M, Herrington $D$, et al.: Guidelines for the ultrasound assessment of endothelial-dependent flow-mediated vasodilation of the brachial artery: a report of the International Brachial Artery Reactivity Task Force. J Am Coll Cardiol 2002, 39(2):257-265.

9. Sacco RL, Kargman DE, Gu Q, Zamanillo MC: Race-ethnicity and determinants of intracranial atherosclerotic cerebral infarction. The Northern Manhattan Stroke Study. Stroke 1995, 26(I): |4-20.

10. Shimbo D, Grahame-Clarke C, Miyake Y, Rodriguez C, Sciacca R, Di Tullio M, Boden-Albala B, Sacco R, Homma S: The association between endothelial dysfunction and cardiovascular outcomes in a population-based multi-ethnic cohort. Atherosclerosis 2007, I 92(I): 197-203.

II. Executive Summary of The Third Report of The National Cholesterol Education Program (NCEP) Expert Panel on Detection, Evaluation, And Treatment of High Blood Cholesterol In Adults (Adult Treatment Panel III). JAMA 200I, 285( I 9):2486-2497.

12. Sacco RL, Elkind M, Boden-Albala B, Lin IF, Kargman DE, Hauser WA, Shea S, Paik MC: The protective effect of moderate alcohol consumption on ischemic stroke. JAMA I999, 28 I(I):53-60.

13. Elkind MS, Sciacca R, Boden-Albala B, Rundek T, Paik MC, Sacco RL: Moderate alcohol consumption reduces risk of ischemic stroke: the Northern Manhattan Study. Stroke 2006, 37(I): 13-19.

14. Block G, Hartman AM, Dresser CM, Carroll MD, Gannon J, Gardner $\mathrm{L}$ : A data-based approach to diet questionnaire design and testing. Am J Epidemiol 1986, I24(3):453-469.

15. Willett WC, Sampson L, Stampfer MJ, Rosner B, Bain C, Witschi J, Hennekens $\mathrm{CH}$, Speizer FE: Reproducibility and validity of a semiquantitative food frequency questionnaire. Am J Epidemiol 1985, I 22(I):51-65.

16. Teragawa H, Fukuda Y, Matsuda K, Higashi Y, Yamagata T, Matsuura $H$, Chayama K: Effect of alcohol consumption on endothelial function in men with coronary artery disease. Atherosclerosis 2002, I 65(I): | 45-152.

17. Joannides R, Haefeli WE, Linder L, Richard V, Bakkali EH, Thuillez C, Luscher TF: Nitric oxide is responsible for flow-dependent dilatation of human peripheral conduit arteries in vivo. Circulation 1995, $91(5): 1314-1319$.

18. Wang $X L$, Wang J: Endothelial nitric oxide synthase gene sequence variations and vascular disease. Mol Genet Metab 2000, 70(4):24I-25I.
19. Pyke KE, Tschakovsky ME: The relationship between shear stress and flow-mediated dilatation: implications for the assessment of endothelial function. J Physiol 2005, 568(Pt 2):357-369.

20. Whelan AP, Sutherland WH, McCormick MP, Yeoman DJ, de Jong SA, Williams MJ: Effects of white and red wine on endothelial function in subjects with coronary artery disease. Intern Med J 2004, 34(5):224-228.

21. Agewall S, Wright S, Doughty RN, Whalley GA, Duxbury M, Sharpe $\mathrm{N}$ : Does a glass of red wine improve endothelial function? Eur Heart J 2000, 2 I (I):74-78.

22. Stein JH, Keevil JG, Wiebe DA, Aeschlimann S, Folts JD: Purple grape juice improves endothelial function and reduces the susceptibility of LDL cholesterol to oxidation in patients with coronary artery disease. Circulation 1999. I00( I0): 1050-1055.

23. Vlachopoulos C, Tsekoura D, Tsiamis E, Panagiotakos D, Stefanadis $C$ : Effect of alcohol on endothelial function in healthy subjects. Vasc Med 2003, 8(4):263-265.

24. Liu J, Tian Z, Gao B, Kunos G: Dose-dependent activation of antiapoptotic and proapoptotic pathways by ethanol treatment in human vascular endothelial cells: differential involvement of adenosine. J Biol Chem 2002, 277(23):20927-20933.

25. Hendrickson RJ, Cahill PA, Sitzmann JV, Redmond EM: Ethanol enhances basal and flow-stimulated nitric oxide synthase activity in vitro by activating an inhibitory guanine nucleotide binding protein. I Pharmacol Exp Ther 1999, 289(3): I293-1300.

26. Venkov CD, Myers PR, Tanner MA, Su M, Vaughan DE: Ethanol increases endothelial nitric oxide production through modulation of nitric oxide synthase expression. Thromb Haemost I999, 8 I (4):638-642.

27. Wallerath T, Poleo D, Li H, Forstermann U: Red wine increases the expression of human endothelial nitric oxide synthase: a mechanism that may contribute to its beneficial cardiovascular effects. J Am Coll Cardiol 2003, 4 I (3):47I-478.

\section{Pre-publication history}

The pre-publication history for this paper can be accessed here:

http://www.biomedcentral.com/1471-2261/9/8/prepub

Publish with Bio Med Central and every
scientist can read your work free of charge
"BioMed Central will be the most significant development for
disseminating the results of biomedical research in our lifetime."
Sir Paul Nurse, Cancer Research UK
Your research papers will be:
- available free of charge to the entire biomedical community
- peer reviewed and published immediately upon acceptance
- cited in PubMed and archived on PubMed Central
• yours - you keep the copyright
Submit your manuscript here:
http://www.biomedcentral.com/info/publishing_adv.asp

